\title{
Construcionalização gramatical sincrônica: evidências a partir da análise de construções avaliativas com "super" e "mega" na língua portuguesa
}

\author{
Lauriê Ferreira Martins Dall'Orto ${ }^{1}$ \\ Patrícia Fabiane Amaral da Cunha Lacerda ${ }^{2}$
}

\begin{abstract}
Resumo: $O$ presente artigo tem por objetivo discutir o lugar da perspectiva sincrônica de análise no âmbito das investigações em construcionalização gramatical. A fim de cumprir o objetivo proposto, foram realizadas as análises qualitativa e quantitativa (CUNHA LACERDA, 2016) das construções avaliativas com "super" e "mega" na língua portuguesa, considerando a distribuição dos dados no português contemporâneo. Neste estudo, assumimos os pressupostos teóricos do modelo proposto por Traugott e Trousdale (2013), principalmente no que tange às definições de língua, de construção e de rede e no que se refere ao processo de construcionalização, e discutimos a nomenclatura "construcionalização gramatical sincrônica" proposta por Rosário e Lopes (2017). Os resultados da pesquisa mostram que, nos estudos acerca da construcionalização gramatical sincrônica de construções avaliativas com "super" e "mega", é possível evidenciar a importante atuação do mecanismo da analogização (TRAUGOTT, 2011a). É nesse contexto que demonstramos, por meio da proposição de uma rede construcional, que microconstruções individuais articulam esquemas gerais e abstratos ao mesmo tempo em que são por eles afetadas.
\end{abstract}

Palavras-chave: Construcionalização gramatical sincrônica. Analogização. Rede construcional.

\section{Introdução}

O presente artigo é um recorte de nossa tese de doutorado, defendida na Universidade Federal de Juiz de Fora em 2018. O objetivo mais geral deste trabalho é discutir o lugar ocupado pela perspectiva sincrônica de análise no âmbito das investigações de processos de construcionalização gramatical.

De modo mais específico, pretendemos evidenciar, por meio do estabelecimento dos níveis esquemáticos e da proposição de uma rede construcional que envolvem as construções avaliativas com "super" e "mega", o papel do mecanismo da analogização na instanciação de novos pareamentos forma-função na língua.

\footnotetext{
${ }^{1}$ Doutora em Linguística pelo Programa de Pós-Graduação em Linguística da Universidade Federal de Juiz de Fora. Atua como bolsista em nível de Pós-Doutoramento, no contexto do Programa Nacional de Pós-Doutorado (PNPD) da CAPES, por meio do Programa de Pós-Graduação em Linguística da Universidade Federal de Juiz de Fora. E-mail: lauriefm@hotmail.com.

${ }^{2}$ Doutora em Linguística pela Universidade Federal de Minas Gerais. Atua como professora adjunta da Faculdade de Letras e do Programa de Pós-graduação em Linguística da Universidade Federal de Juiz de Fora. E-mail: patriciafabianecunha@gmail.com.
} 
A escolha pelas construções avaliativas com "super" e "mega", como objetos de investigação neste artigo, deve-se ao fato de, além se serem altamente frequentes na língua portuguesa na atualidade, indexarem conceptualizações distintas - enquanto "super" indexa uma projeção metafórica de localização para cima (intensidade é localização); "mega" indexa uma projeção metafórica de tamanho (intensidade é tamanho/dimensão). E, de acordo com Traugott (2011b), as metáforas podem motivar a emergência de novos padrões construcionais, atuando como uma representação exemplar. Observemos os exemplos a seguir:

(1) "Estou superfeliz com o convite, mas ainda não tenho muitos detalhes sobre a personagem", disse Grazi, que, em 2006, viveu a Telminha de Páginas da Vida e, em 2007, a Flor de Desejo Proibido. (Corpus 2008 - Nível de formalidade 2)

(2) Escolhi a cor 94, um bege meio cor de burro quando foge. Não havia provadores, e me decepcionei quando testei em casa: MEGA brilhoso, e eu querendo alguma coisa sem brilho. Quando passei na boca, não espalhou direito, bem esquisito. Só me entendi com ele quando espalhei o batom com o dedo, só ficou a corzinha e o brilho foi embora. Fiquei com ele a tarde toda, comi e bebi, e até que durou. Tem cheiro leve de chocolate, não me incomodou em nada, eu, a pessoa com problema com cheiros. (Corpus 2008 - Nível de formalidade 1$)^{4}$

Nos exemplos (1) e (2) acima, "super" e "mega" cumprem propósitos comunicativos específicos na língua que diferem de seus usos como prefixo. Em (1), “super” desempenha a função como advérbio de intensidade, tendo como escopo o adjetivo "feliz". Através da construção "superfeliz", a locutora exprime uma avaliação positiva sobre si mesmo ao comentar sobre o convite recebido para atuação em uma nova novela. Nessa ocorrência, "super" também atua como um operador da focalização, uma vez que a locutora coloca em relevo aquilo que ela pretende dar proeminência em seu discurso (“feliz”). Em (2), a locutora expressa, por meio da construção "MEGA brilhoso", uma avaliação negativa acerca de determinado batom. Nesse exemplo, "mega" também atua como advérbio de intensidade e como operador da focalização, cujo escopo é o adjetivo "brilhoso", que também é o elemento que recebe foco no discurso. Nesse sentido, denominamos "avaliativas" às construções em

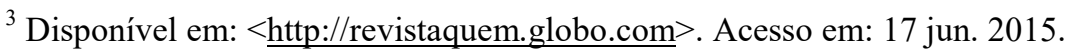

${ }^{4}$ Disponível em: <http://www.vendenafarmacia.com.br/2008/08/batom-marcelo-beauty-linha-essencial.html>. Acesso em: 9 jun. 2015.

${ }^{5}$ Apesar de não termos nos dedicado a uma análise da ortografia das construções, a nossa hipótese é a de que a escrita conjugada ("superfeliz") reflete o entendimento de tais construções, ainda, como construções prefixais;por outro lado, a escrita separada, mais frequente em contextos mais informais, reflete a representação das construções avaliativas da mente do locutor.
} 
que "super" e "mega" indexam o posicionamento avaliativo do locutor, por meio da intensificação e da focalização, acerca de si mesmo, de alguém, de algo ou da própria proposição.

A fim de cumprir com os objetivos propostos, tomamos como base os conceitos de língua, de construção, de rede e de construcionalização do modelo de Traugott e Trousdale (2013) e a proposição de "construção gramatical sincrônica" de Rosário e Lopes (2017). Como metodologia, adotamos uma perspectiva sincrônica de análise a partir do método misto de investigação dos dados (CUNHA LACERDA, 2016).

Dessa maneira, o presente artigo organiza-se da seguinte forma: (i) primeiramente, apresentamos os postulados do modelo de Traugott e Trousdale (2013) que são caros a este trabalho; (ii) em seguida, discutimos a proposição da nomenclatura "construcionalização gramatical sincrônica" de Rosário e Lopes (2017); (iii) apresentamos os procedimentos metodológicos da pesquisa; (iv) realizamos a análise das construções avaliativas com "super" e "mega"; (v) e, por fim, explicitamos nossas considerações acerca do estudo empreendido.

\section{O modelo de Traugott e Trousdale (2013)}

Diferentes abordagens teóricas, desde a Antiguidade Clássica, vêm sendo postuladas para explicar a mudança linguística. No âmbito do funcionalismo clássico, de vertente norteamericana, destacamos os processos de gramaticalização e de lexicalização, que, ainda que em uma perspectiva tradicional, despertaram a atenção dos estudiosos por muito tempo (ROSÁRIO \& OLIVEIRA, 2016). Em contrapartida, pautado nos postulados do funcionalismo contemporâneo - recentemente denominado Linguística Funcional Centrada no Uso $(\mathrm{LFCU})^{6}$ pelos estudiosos da área para se referir às pesquisas funcionalistas que comungam determinados conhecimentos desenvolvidos no âmbito do funcionalismo clássico

\footnotetext{
${ }^{6}$ Linguística Funcional Centrada no Uso é a denominação atribuída por Martelotta (2011), Furtado da Cunha et al. (2013), Rosário e Oliveira (2016), Bispo e Silva (2016), dentre outros, no âmbito dos estudos do grupo Discurso \& Gramática. Autores como Bybee (2010) e Traugott e Trousdale (2013) utilizam a denominação Usage-based Theory/Approach.
} 


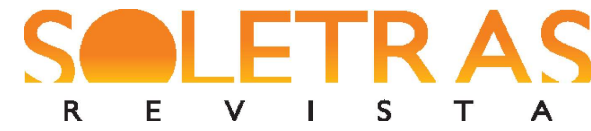

R
S
T A

LAURIÊ FERREIRA MARTINS DALL'ORTO

PATRICIA FABIANE AMARAL DA CINHA LACERDA

e da Gramática de Construções ${ }^{7}$-, destacamos o interesse dos pesquisadores pelos processos de construcionalização e de mudança construcional.

Em sua obra intitulada Constructionalization and Constructional Changes, Traugott e Trousdale (2013) propõem um novo modelo teórico para a investigação da mudança linguística a partir das dimensões da construcionalização e da mudança construcional, tanto lexical quanto gramatical, tendo como concepção de língua uma rede taxonômica de construções organizadas e associadas hierarquicamente.

Tal modelo trata da mudança linguística a partir da noção de construção, isto é, da correspondência simbólica e convencionalizada entre aspectos da forma (fonologia, morfologia e sintaxe) e aspectos da função ${ }^{8}$ (semântica, pragmática e discurso), possibilitando, inclusive, a observação de instanciações linguísticas e de suas relações com outras construções em uma rede construcional composta por níveis esquemáticos e hierárquicos (TRAUGOTT \& TROUSDALE, 2013).

Nessa perspectiva, a língua é entendida como sendo formada por um conjunto de construções que se organizam hierarquicamente em torno de uma rede taxonômica comum, ou seja, uma rede de nós interligados por elos, de modo que as associações entre os nós se estabelecem de maneira hierárquica (TRAUGOTT \& TROUSDALE, 2013).

A construcionalização diz respeito ao processo de mudança linguística que tem como resultado a emergência de um novo pareamento forma-função na língua, a partir das necessidades comunicativas dos falantes no momento da interação, bem como à sua integração à rede construcional. De acordo com Traugott e Trousdale (2013), a construcionalização gramatical pressupõe sucessões de neoanálises ${ }^{9}$ morfossintáticas e semântico-pragmáticas, constituindo um processo de mudança gradual e discreto de uma construção de caráter mais procedural. Por outro lado, a construcionalização lexical constitui

\footnotetext{
${ }^{7}$ Da Gramática de Construções, a LFCU se apropria, por exemplo, dos conceitos de construção e de rede, nos termos de Goldberg $(1995,2006)$ e Croft (2001).

8 Embora Traugott e Troudale (2013) adotem o termo "sentido" para designar os aspectos semânticos, pragmáticos e discursivos da construção, neste artigo, assumimos o termo "função", de acordo com Goldberg (2016), devido ao fato de este ser mais abrangente.

${ }^{9}$ A neoanálise é um mecanismo de mudança linguística que consiste em uma nova interpretação de uma forma já existente com uma nova função e/ou de uma função já existente com uma nova forma. O mecanismo da neoanálise é responsável pelo alinhamento entre padrões gramaticais e padrões de uso, a partir da negociação de sentido entre os participantes da situação comunicativa, e envolve diretamente a noção de (inter)subjetivização (TRAUGOTT, 2008, 2011c; TRAUGOTT \& TROUSDALE, 2013). Para maiores informações sobre o processo de (inter)subjetivização, ver Traugott e Dasher (2005).
} 
um processo de mudança linguística geralmente instantânea de uma construção de natureza mais referencial.

Já a mudança construcional consiste em um processo de mudança em um determinado nível linguístico de uma construção - fonologia, morfologia, sintaxe, semântica, pragmática ou discurso -, sem resultar na criação de um novo pareamento forma-função na língua. Assim como a construcionalização, a mudança construcional também constitui um processo de mudança que se dá em pequenos passos (ou small-steps), a partir de uma sucessão de neoanálises (TRAUGOTT \& TROUSDALE, 2013).

Segundo Traugott e Trousdale (2013), a mudança construcional pode ocorrer antes ou depois da construcionalização. Os autores denominam "pré-construcionalização" o processo linguístico em que mudanças construcionais precedem a construcionalização - tais como semanticização, expansão pragmática, mismatchentre forma e função e pequenas mudanças distribucionais -; e denominam "pós-construcionalização" o processo em que mudanças construcionais sucedem a construcionalização - como, por exemplo, expansão colocacional (host-class) e mudança de categoria, redução morfológica e fonológica e perda e obsolescência.

Uma vez que Traugott e Trousdale (2013) assumem, no âmbito da construcionalização e da mudança construcional, a noção de rede como um inventário de construções que se relacionam de maneira hierárquica, julgamos que o estabelecimento dos níveis de esquematicidade que envolvem as construções pode não somente auxiliar na compreensão da mudança linguística em micropassos, mas também evidenciar o resultado de um processo de construcionalização a partir da perspectiva da analogização - alinhamento ou correspondência simbólica de um novo pareamento a um esquema mais abstrato já fixado na língua.

Traugott e Trousdale (2013) propõem três níveis esquemáticos, a saber, esquema, subesquema e microconstrução, para demonstrar os graus de generalidade e de especificidade das construções em uma rede construcional. A esse respeito, os autores afirmam o seguinte:

Alguns nós na rede representam esquemas, outros, subesquemas, e outros, microconstruções. Portanto, um nó tem conteúdo de forma e sentido [...] e links possíveis em múltiplas direções diferentes, entre semântica, pragmática, função discursiva, sintaxe, morfologia e fonologia de qualquer nó. Cada nó é ligado de várias maneiras para outros nós em uma rede. 
(TRAUGOTT \& TROUSDALE, 2013, p. 51, tradução nossa, destaque nosso)

Segundo os autores, a representação simbólica mais geral e mais abstrata da rede construcional é denominada esquema linguístico. É o esquema linguístico que apresenta diversas possibilidades de preenchimento (slots). Já os subesquemas são entendidos pelos autores como sendo níveis intermediários que agrupam construções individuais que possuem similaridades entre si. Por fim, as microconstruções são construções individuais particulares, que preenchem os slots dentro dos subesquemas (TRAUGOTT \& TROUSDALE, 2013).

Nesse sentido, o mapeamento do esquema, dos subesquemas e das microconstruções avaliativas com "super" e "mega", neste artigo, tem por objetivo auxiliar na compreensão da instanciação e da convencionalização de novas construções na língua - não a partir da perspectiva dos micropassos, mas do ponto de vista da analogização -, bem como no entendimento das relações entre as construções em uma rede construcional comum.

As construções avaliativas com "super" e "mega", que têm sentido mais procedural, se enquandram, sim, no escopo da construcionalização gramatical, mesmo sendo analisadas em uma amostra sincrônica, uma vez que tiveram seus padrões de uso expandidos em diferentes contextos a fim de cumprirem propósitos comunicativos específicos.

Sendo assim, nas próximas seções, tratamos do lugar ocupado pela análise sincrônica no âmbito do modelo teórico proposto por Traugott e Trousdale (2013), principalmente no que tange à construcionalização gramatical, e de sua relação com o mecanismo da analogização.

\section{Construcionalização gramatical sincrônica: uma proposição}

Uma vez que a construcionalização gramatical, segundo Traugott e Trousdale (2013), diz respeito ao processo de mudança linguística processada em micropassos, a partir de uma sucessão de neoanálises morfossintáticas e semântico-pragmáticas graduais e discretas - isto é, refere-se à mudança linguística que ocorre através do tempo -, que tem como resultado novos pareamentos forma-função na língua, a questão que procuramos discutir neste artigo é a 
seguinte: seria possível a investigação da construcionalização gramatical mediante uma perspectiva sincrônica de análise?

De acordo com Rosário e Lopes (2017), embora o modelo teórico de Traugott e Trousdale (2013) tenha sido desenvolvido para o estudo de fenômenos diacrônicos que ocorrem na língua, este é capaz de dar conta das instanciações que estão ocorrendo na língua em tempo presente. É nesse contexto que os autores propõem a denominação "construcionalização gramatical sincrônica".

Para os autores, a mudança linguística não ocorre apenas na diacronia. Sendo assim, Rosário e Lopes (2017) enumeram cinco justificativas que sustentam sua proposição para a construcionalização gramatical sincrônica.

Rosário e Lopes (2017), primeiramente, verificam que [1] o conceito de mudança presente nos estudos sociolinguísticos de Labov (2008) já admitiria o trabalho com a sincronia. Segundo os autores, Labov (2008) considera que a mudança linguística só pode ser entendida quando se leva em conta a vida social da comunidade em que ela ocorre. Dito de outro modo, para Labov (2008, p. 21), pressões sociais operam continuamente sobre a língua “como uma força imanente agindo no presente vivo". É nesse contexto que Rosário e Lopes (2017) concluem que, se a mudança linguística pode ser compreendida a partir de dados sincrônicos, consequentemente não seria diferente com o processo de construcionalização.

Posteriormente, Rosário e Lopes (2017) destacam que [2] o próprio conceito de língua de Traugott e Trousdale (2013, p. 44, tradução nossa), a partir de Bybee (2010, p. 1), pressupõe que a análise sincrônica é coerente com os estudos em mudança, conforme observamos a seguir: “(...) a língua é um fenômeno que exibe estrutura aparente e regularidade de padrões ao mesmo tempo em que apresenta considerável variação em todos os níveis". Os autores ressaltam, ainda, que a variação sincrônica é garantida pelo princípio da estratificação de Hopper (1991), que se refere à emergência de novas construções e à coexistência com construções já convencionalizadas na língua.

A terceira justificativa dos autores é a de que [3] Traugott e Trousdale (2013) admitem a correlação gradualidade e gradiência quando assumem que as mudanças linguísticas apresentam uma pequena escala de gradiência, que se manifesta na variação.

Atrelado a isso, Rosário e Lopes (2017) defendem que [4] haveria um correlato construcionalização diacrônica e construcionalização sincrônica, assim como há a correlação 
gramaticalização e gramaticalidade. Os autores se apoiam nos pressupostos de Hopper e Traugott (1997), que assumem que a gramaticalização poderia ser concebida em termos de um continuum de gramaticalidade, e de Lehmann (1985), que propõe seis critérios para a aferição do grau de gramaticalidade de um item.

Por último, Rosário e Lopes (2017) argumentam que [5] os próprios modelos de gramática de construções adotados no âmbito dos estudos em Linguística Funcional Centrada no Uso foram pensados originalmente para a representação do conhecimento linguístico na mente dos falantes, e não para a mudança linguística, como é o caso da Gramática de Construções Radical de Croft (2001).

Além de todas as justificativas apresentadas por Rosário e Lopes (2017), acrescentamos, ainda, que uma análise sincrônica dos dados nos permite, também, observar a extensibilidade de padrões a partir da perspectiva da analogização, sem necessariamente negarmos a mudança linguística em micropassos - isto é, do ponto de vista de uma sucessão de neoanálises. A analogização, segundo Martins Dall'Orto (2018, p. 38),

(...) refere-se ao mecanismo que leva à combinação entre aspectos da forma e da função de uma construção-alvo e aspectos da forma e da função de uma construção-fonte. O mecanismo da analogização envolve, portanto, a reconfiguração das dimensões internas da construção, tendo como base uma construção já existente, com a qual seja possível fazer a correspondência (MARTINS DALL'ORTO, 2018, p. 38).

É nesse sentido que objetivamos, neste trabalho, demonstrar que a análise sincrônica dos dados é capaz de refletir a atração morfossintática e semântico-pragmática e a extensibilidade de padrões a partir de exemplos. Em outras palavras, assumimos, aqui, ser possível atestar a dinamicidade da língua mesmo na sincronia, com ênfase na analogização mecanismo que, juntamente com a neoanálise e a frequência de uso (TRAUGOTT, 2011a; TRAUGOTT \& TROUSDALE, 2013), promovem a construcionalização gramatical. Desse modo, neste artigo, não defendemos que as construções avaliativas com "super" e "mega" tenham passado por um processo de mudança instantâneo. $\mathrm{Na}$ verdade, acreditamos na sucessão de neoanálises dessas construções, embora tenhamos optado por demonstrar a mudança linguística do ponto de vista da analogização. 
Portanto, embora entendamos que o modelo de Traugott e Trousdale (2013) tenha sido pensado para o tratamento de fenômenos diacrônicos na língua - conforme também apontam Rosário e Lopes (2017) -, acreditamos que ele seja, sim, capaz de fornecer ferramentas para pensarmos na maneira com que microconstruções individuais articulam esquemas gerais ao mesmo tempo em que são por eles afetadas mesmo em uma amostra sincrônica.

\section{Procedimentos metodológicos}

Uma vez que o objetivo deste artigo é demonstrar que a construcionalização gramatical pode ser depreendida a partir de uma perspectiva sincrônica de análise, com foco no mecanismo da analogização, utilizamos como amostra para a investigação dos dados textos escritos datados do século XXI.

De acordo com Neves (1997), o foco do estudo sincrônico é a descrição dos padrões de uso para o entendimento do sistema linguístico, bem como a possibilidade de uma relação entre inovações e construções já existentes na língua.

Defendemos, neste artigo, que a perspectiva sincrônica de análise

(...) reflete, sim, a dinamicidade da língua, que está em constante processo de variação e mudança e de instanciação de novos padrões cosntrucionais, uma vez que formas e funções velhas e novas podem coexistir, em determinado momento, tanto em seu estatuto original quanto em seu estatuto construcionalizado (MARTINS DALL'ORTO, 2018, p. 112).

É com base no excerto acima que atribuímos a devida importância à perspectiva sincrônica de análise. Além de atestar pareamentos forma-função resultantes de expansões semântico-pragmáticas e morfossintáticas que ocorrem no curso da interação comunicativa, o estudo sincrônico possibilita, ainda, a identificação dos níveis de esquematicidade que organizam as construções em torno de uma rede construcional comum via mecanismo da analogização. 
Nossa amostra sincrônica é composta por textos da modalidade escrita da língua, os quais foram extraídos de blogs e de revistas online e distribuídos em três níveis de formalidade. A composição da amostra foi realizada com base nas seguintes diretrizes estabelecidas por Vitral (2006): (i) diversidade de gêneros textuais e (ii) mesmo recorte de número de palavras (ou número aproximado). Observemos o quadro abaixo:

\begin{tabular}{|c|l|c|}
\hline $\begin{array}{c}\text { Nível de } \\
\text { formalidade }\end{array}$ & \multicolumn{1}{|c|}{ Descrição do nível de formalidade } \\
\hline $\begin{array}{c}\text { Nível de } \\
\text { formalidade 1 }\end{array}$ & Blogs pessoais que tratam de temas do cotidiano. & $\begin{array}{c}\text { Total de número de palavras } \\
\text { analisadas }\end{array}$ \\
\hline $\begin{array}{c}\text { Nível de } \\
\text { formalidade 2 }\end{array}$ & Revistas que tratam de temas do cotidiano. & 900.000 \\
\hline $\begin{array}{c}\text { Nível de } \\
\text { formalidade 3 }\end{array}$ & $\begin{array}{l}\text { Revistas que tratam de temas de maior impacto } \\
\text { nacional e internacional. }\end{array}$ \\
\hline
\end{tabular}

Quadro 1 - Corpus sincrônico escrito

Após o levantamento das ocorrências no corpus selecionado, cada uma delas foi detalhadamente contabilizada e interpretada, a partir do método misto de análise (CUNHA LACERDA, 2016) - análise qualitativa e cálculo da frequência de uso -, no que tange aos seus aspectos formais e funcionais.

\section{As construções avaliativas com "super" e "mega"}

Demonstramos, nesta seção do artigo, de que maneira construções avaliativas com "super" e "mega", que teriam sido moldadas no e pelo contexto de uso e integradas à gramática da língua, se enquadram no escopo do processo de construcionalização gramatical nos termos de Traugott e Trousdale (2013) - ou da "construcionalização gramatical sincrônica", nos termos de Rosário e Lopes (2017).

Para tanto, descrevemos, nesta seção, os pareamentos forma-função das construções avaliativas com "super" e "mega" na língua portuguesa a partir de uma proposta de rede esquemática que os relacione de maneira hierárquica em torno de um esquema abstrato comum $-\left\{[\mathrm{X}]_{\mathrm{op}}+[\mathrm{Y}]_{\mathrm{var}}\right\}^{\mathrm{int} / \text { foc }}-$, conforme representado a seguir: 
SOLETRAS

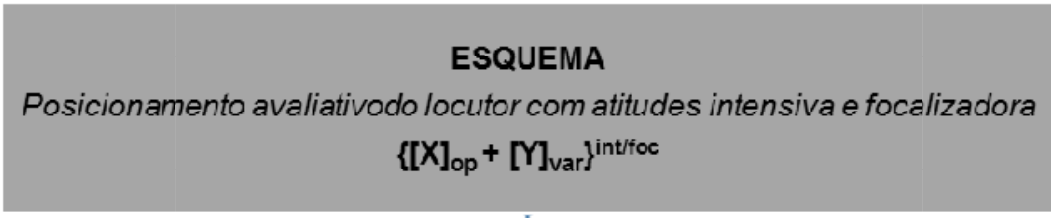

\section{SUBESQUEMA 1}

Foc.; intens. explicita; ancoragem [+ intersubjetiva]

$\left\{[X]_{o p}+[\mathrm{adj} / \mathrm{adv}]_{\mathrm{var}}\right\}^{\text {Intffoc }}$

\section{SUBESQUEMA 2}

Foc.; intens. implícita; ancoragem [+ intersubjetiva] do que o subesquema1; qualificação

$\left\{[X]_{o p}+[\text { subs }]_{\text {var }}\right.$ Jntifoc

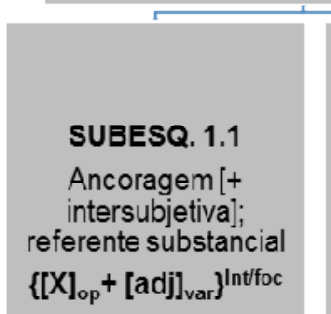

$\left\{[\mathrm{X}]_{\text {op }}+[\operatorname{adj}]_{\text {var }}\right]^{\text {Intfoc }}$

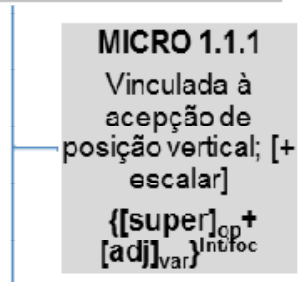

MICRO 1.1.2

Vinculada à acepção de tamanho; [+ escalar] do que a micro 1.1.1

\{[mega] $]^{+}$ [adj] var $\}_{\text {nffoc }}^{+}$

MICRO 1.1.3

Vinculada à acepção de posição vertical; [+ escalar] do que a micro 1.1.1 [ahiper] $]_{\text {ap }}^{+}$

MICRO 1.1.4

Vinculada à acepção de posição horizontal;

[+ escalar] do que a micro 1.1 . [[ultra] $]_{\text {[adj] }}^{+}$

\section{SUBESQ. 1.2}

Ancoragem [+ intersubjetiva]; referente relativo a ações, estado de coisas $\in$ eventos $\left\{[X]_{o p}+[a d v]_{\text {var }}\right\}$ Intfoc

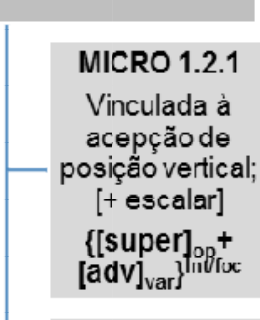

MICRO 1.2.2

Vinculada à acepção de tamanho: [+ escalar] do que a micro 1.2.1

\{[mega] ${ }^{+}$ $\left.[a d v]_{\text {var }}\right]_{\text {inffoc }}$

MICRO 1.2.3

Vinculada à acepção de posiçấo vertical; [+ escalar] do que a micro 1.2.1

[Thiper] + [adv $\left.]_{\text {var }}\right]^{\text {Int }}$ foc

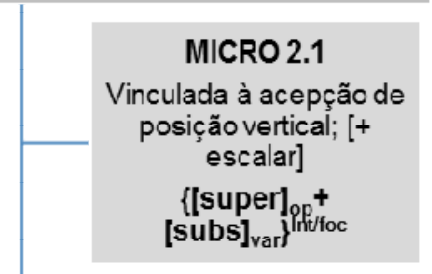

MICRO 2.2

Vinculada à acepção de tamanho; [+ escalar] do que a micro 2.1

$\left\{[\text { mega }]_{u p}+[\text { subs }]_{\text {var }}\right\}^{\text {Intfoc }}$

MICRO 2.3

Vinculada à acepção de posição vertical; [+ escalar] do que a micro 2.1

\section{MICRO 2.4}

Vinculada à acepção de posição horizontal; [+ escalar] do que a micro 2.1 $\left\{[\text { ultra }]_{o p}+[\text { subs }]_{\text {var }}\right\}^{\text {Inttoc }}$ [lhiper $]_{\mathrm{op}}+[\text { subs }]_{\mathrm{var}}$ Jntffoc

\section{SUBESQUEMA 3}

Foc ; intens implícita; ancoragem [+ intersubjetiva] do que os subesquemas 1 e 2; modalização $\left\{[\mathrm{X}]_{\mathrm{op}}+[\text { verb }]_{\text {var }}\right\}$ \}nt/foc

\section{MICRO 3.1}

Vinculada à acepção de posiçãovertical: [+ escalar] \{[super] op
[verb] $\left.]_{\text {var }}\right\}^{\text {Inifo }}$

\section{MICRO 3.2}

Vinculada à acepção de tamanho: [+ escalar] do que a micro 3.1

[lmega] ${ }_{\text {op }}^{+}$ [verb] ] $]_{\text {var }}$ intfoc 
Figura 1 - Rede construcional das construções avaliativas com "super", "mega", "hiper” e "ultra” na língua portuguesa

Fonte: Martins Dall’Orto (2018, p. 209)

Defendemos, neste artigo, que as construções avaliativas com "super" e "mega" constituem pareamentos pertencentes a um esquema mais abstrato e mais geral, cuja configuração formal e funcional pode ser observada no quadro abaixo:

\begin{tabular}{|c|c|}
\hline \multicolumn{2}{|c|}{ ESQUEMA } \\
\hline Função & Posicionamento avaliativo do locutor com atitudes intensiva e focalizadora \\
\hline Forma & $\left\{[\mathrm{X}]_{\mathrm{op}}+[\mathrm{Y}]_{\mathrm{var}}\right\}^{\text {int/foc }}$ \\
\hline & Quadro 2 - Configuração funcional e formal do esquema \\
Fonte: Martins Dall'Orto (2018, p. 166)
\end{tabular}

O esquema linguístico representado por $\left\{[\mathrm{X}]_{\mathrm{op}}+[\mathrm{Y}]_{\mathrm{var}}\right\}^{\mathrm{int} / \mathrm{foc}}$ é composto por dois slots, isto é, por duas possibilidades de preenchimento por estruturas simbólicas, $\mathrm{X}$ e $\mathrm{Y}$, as quais são recrutadas pelo locutor para, através das propriedades da intensificação e da focalização (int/foc), indexar um posicionamento avaliativo do locutor sobre si mesmo, sobre alguém, sobre algo ou sobre a própria proposição. O primeiro slot, denominado operador (op), é preenchido por intensificadores e focalizadores, tais como "super", "mega", "hiper" e/ou "ultra"; o segundo slot, denominado variável (var), é preenchido por elementos intensificados e focalizados, que podem ser um adjetivo, um advérbio, um substantivo ou um verbo.

Três subesquemas, relacionados ao esquema linguístico descrito, foram por nós identificados. Os três diferentes subesquemas se diferenciam formal e funcionalmente em função do escopo da intensificação e da focalização (se adjetivo, se advérbio, se substantivo, se verbo) e, por conseguinte, do papel morfossintático exercido por "super", "mega", "hiper" e "ultra" nas construções (se advérbio de intensidade, se adjetivo qualificativo, se advérbio modalizador). Cada um dos subesquemas agrupa microconstruções que possuem semelhanças no que tange aos seus aspectos formais e funcionais. Observemos, no quadro abaixo, os pareamentos forma-função dos três subesquemas identificados: 


\begin{tabular}{|c|c|c|}
\hline \multicolumn{3}{|r|}{ SUBESQUEMAS } \\
\hline \multirow[t]{2}{*}{ Subesquema 1} & Função & $\begin{array}{l}\text { Focalização } \\
\text { Intensificação explícita } \\
\text { Ancoragem [+ intersubjetiva] }\end{array}$ \\
\hline & Forma & $\left\{[\mathrm{X}]_{\text {op }}+[\mathrm{adj} / \mathrm{adv}]_{\mathrm{vara}}\right\}^{\text {int/foc }}$ \\
\hline \multirow[t]{2}{*}{ Subesqueта 2} & Função & $\begin{array}{l}\text { Focalização } \\
\text { Intensificação implícita } \\
\text { Ancoragem [+ intersubjetiva] do que no subesquema } 1 \\
\text { Qualificação }\end{array}$ \\
\hline & Forma & $\left\{[\mathrm{X}]_{\mathrm{op}}+[\mathrm{subs}]_{\mathrm{var}}\right\}^{\text {intfoc }}$ \\
\hline \multirow[t]{2}{*}{ Subesquema 3} & Função & $\begin{array}{l}\text { Focalização } \\
\text { Intensificação implícita } \\
\text { Ancoragem [+ intersubjetiva] do que nos subesquemas } 1 \text { e } 2 \\
\text { Modalização }\end{array}$ \\
\hline & Forma & $\left\{[\mathrm{X}]_{\mathrm{op}}+[\mathrm{verb}]_{\mathrm{var}}\right\}^{\text {int/foc }}$ \\
\hline
\end{tabular}

Quadro 3 - Configuração funcional e formal dos subesquemas

Fonte: Martins Dall'Orto (2018, p. 168)

Verificamos, no Quadro 3 acima, que

(a) o subesquema 1 articula focalização e intensificação explícita $-\left\{[\mathrm{X}]_{\mathrm{op}}+[\operatorname{adj} / \mathrm{adv}]_{\mathrm{var}}\right\}^{\mathrm{int} / \mathrm{foc}}$;

(b) o subesquema 2 indexa, além da focalização e da intensificação implícita, a propriedade da qualificação $-\left\{[\mathrm{X}]_{\mathrm{op}}+[\mathrm{subs}]_{\mathrm{var}}\right\}^{\mathrm{int} / \mathrm{foc}} ; \mathrm{e}$

(c) o subesquema 3 exprime focalização, intensificação implícita e modalização - $\left\{[\mathrm{X}]_{\mathrm{op}}+\right.$ $\left.[\mathrm{verb}]_{\mathrm{var}}\right\}^{\mathrm{int} / \mathrm{foc}}$.

Observemos, na Tabela 1 abaixo, a distribuição quantitativa dos subesquemas no corpus sincrônico analisado:

Tabela 1 - Distribuição dos subesquemas no corpus sincrônico

\begin{tabular}{|c|c|c|c|c|c|c|c|}
\hline \multirow{2}{*}{ Corpora } & \multicolumn{2}{|c|}{ Subesquema 1 } & \multicolumn{2}{c|}{ Subesquema 2 } & \multicolumn{2}{c|}{ Subesquema 3 } & \multirow{2}{*}{ Total } \\
\cline { 2 - 8 } & $\mathrm{n}^{\mathbf{0}}$ & $\mathbf{\%}$ & $\mathrm{n}^{\mathbf{0}}$ & $\%$ & $\mathrm{n}^{\mathbf{o}}$ & $\%$ & \\
\hline Nível de formalidade 1 & 1769 & 79,4 & 300 & 13,5 & 159 & 7,1 & 2228 \\
\hline Nível de formalidade 2 & 219 & 83,6 & 41 & 15,6 & 2 & 0,8 & 262 \\
\hline Nível de formalidade 3 & 19 & 39,6 & 29 & 60,4 & - & - & 48 \\
\hline Total & 2007 & 79,1 & 370 & 14,6 & 161 & 6,3 & 2538 \\
\hline
\end{tabular}

Fonte: Martins Dall'Orto (2018, p. 173) 
O que a Tabela 1 nos mostra é que o subesquema 1 é o mais frequente no corpus analisado, compreendendo $79,1 \%$ dos dados encontrados. O subesquema 2 é composto por 14,6\% dos dados, e o subesquema 3 compreende $6,3 \%$ das ocorrências. A Tabela 1 evidencia, ainda, que os três subesquemas são mais representativos em blogs (nível de formalidade 1), onde a linguagem é menos monitorada pelo locutor e menos padronizada no que se refere às regras gramaticais, aproximando-se da modalidade oral da língua.

Em cada um dos três subesquemas, diferentes microconstruções são agrupadas por suas similaridades, conforme observamos na tabela abaixo:

Tabela 2 - Distribuição de microconstruções com “super”, "mega”, "hiper” e "ultra” por subesquema

\begin{tabular}{|c|c|c|c|c|}
\hline Subesquema & $\begin{array}{c}\text { Micros com } \\
\text { "super" }\end{array}$ & $\begin{array}{c}\text { Micros com } \\
\text { "mega" }\end{array}$ & $\begin{array}{c}\text { Micros com } \\
\text { "hiper" }\end{array}$ & $\begin{array}{c}\text { Micros com } \\
\text { "ultra" }\end{array}$ \\
\hline Subesquema 1 & 1763 & 150 & 39 & 55 \\
\hline Subesquema 2 & 244 & 124 & 1 & 1 \\
\hline Subesquema 3 & 159 & 2 & - & - \\
\hline TOTAL & 2166 & 276 & 40 & 56 \\
\hline
\end{tabular}

A partir do levantamento da frequência token de construções avaliativas com "super", "mega", "hiper" e "ultra" no corpus de investigação, verificamos que as construções com “super" são as mais frequentes. Em um universo de 2.538 ocorrências, 2.166 (85,3\%) são de construções intensivas/focalizadoras com "super".

Tabela 3 - Frequência das diferentes funções de construções com "super"

\begin{tabular}{|c|c|c|}
\hline \multirow{2}{*}{ Funções desempenhadas por construções com } & \multicolumn{2}{|c|}{ Frequência } \\
\cline { 2 - 3 } "super" & $\mathbf{n}^{\mathbf{0}}$ & $\mathbf{\%}$ \\
\hline “super” com função de advérbio de intensidade & 1763 & 81,4 \\
\hline "super" com função de adjetivo qualificativo & 244 & 11,3 \\
\hline “super” com função de modalizador epistêmico & 159 & 7,3 \\
\hline Total & \multicolumn{2}{|c|}{2166} \\
\hline
\end{tabular}

Fonte: Martins Dall'Orto (2018, p. 126)

Observamos na Tabela 3 que, em um total de 2.166 ocorrências de construções avaliativas com “super", "super” desempenha três diferentes funções morfossintáticas: 
(i) advérbio de intensidade (1.763 ocorrências);

(ii) adjetivo qualificativo (244 ocorrências);

(iii) advérbio modalizador epistêmico (159 ocorrências).

No corpus selecionado, a função morfossintática de advérbio de intensidade é, consideravelmente, a mais frequente. Por essa e outras razões, a nossa hipótese é a de que a instanciação da construção $\left\{[\mathrm{X}]_{\mathrm{op}}+[\mathrm{Y}]_{\mathrm{var}}\right\}^{\text {int/foc }}$ na língua portuguesa tem como exemplar um esquema construcional já fixado na língua - [advérbio de intensidade] + [adjetivo/advérbio] -, cujo principal representante é o advérbio de intensidade canônico "muito", anteposto a adjetivo ou a advérbio ${ }^{10}$.

Nesse contexto, assumimos que a instanciação de construções avaliativas com "super", "mega", "hiper" e "ultra" não é fortuita. Não é por acaso que o locutor aciona "super", "mega", "hiper" e/ou "ultra" para preencher o slot da intensificação e da focalização e, posteriormente, da qualificação e da modalização, a fim de exprimir um posicionamento avaliativo acerca de si mesmo, de alguém de algo ou de uma proposição. A esse respeito, Martins Dall'Orto (2018, p. 130) considera o seguinte:

Diante da necessidade de ser cada vez mais expressivo, o usuário da língua, mediante o mecanismo da analogização, cria um link de associação metafórica entre "super", prefixo latino que indica posição vertical superior (como em "superpor") - conforme já observado por Silva (2001, p. 119) -, e "muito", advérbio de intensidade. Silva (2014) denomina tal projeção metafórica de Intensidade é localização. O autor retoma o esquema proposto por Lakoff e Johnson (1999) que diz que mais é para cima ou para baixo, dependendo da perspectiva adotada. É nesse sentido que "super" é escolhido para compor o esquema da construção avaliativa intensivo-focalizadora.

Objetivando ser cada vez mais expressivo em suas interações comunicativas, o locutor tende a recorrer a novas formas que possam preencher, assim como "super", o slot da intensificação e da focalização - como são os casos da formas "mega", "hiper" e "ultra". A partir do mecanismo da analogização, "mega", "hiper" e "ultra" também são metaforizados,

${ }^{10}$ Para maiores considerações acerca da analogização com o advérbio de intensidade "muito", ver Martins Dall’Orto (2018). 
no eixo paradigmático, como advérbios de intensidade - e, posteriormente, como adjetivos qualificativos e como advérbios modalizadores epistêmicos asseverativos, conforme demonstramos adiante.

Neste trabalho, tratamos, pontualmente, das construções avaliativas com "super" e "mega", que ocorrem nos três subesquemas identificados.

A convencionalização de "super" com função de advérbio de intensidade, a partir de sua reiteração de uso na comunidade linguística, o transforma em um importante exemplar para a emergência de novas construções na língua. É a partir do pareamento $\left\{[\text { super }]_{\mathrm{op}}{ }^{+}\right.$ $\left.[\mathrm{adj} / \mathrm{adv}]_{\text {var }}\right\}^{\text {int/foc }}$ que novos padrões surgem tanto no eixo sintagmático quanto no eixo paradigmático. Observemos as ocorrências a seguir:

(3) Às vezes eu vejo que ela errou e pintou demais o olho, mas eu até gosto de ver que ela está ousando. Mesmo assim, eu digo: "Ah, presidenta. Comigo eu passo um pouquinho só de preto e a senhora fica reclamando. Ai, quando está sozinha, a senhora passa um pretão". No dia do sorteio da Copa do Mundo, ela estava no calor do Rio de Janeiro e apareceu supersuada. Eu liguei para perguntar o que tinha acontecido e quando a encontrei falei sem meias palavras: "Presidenta do céu! E a cara toda oleosa?" Ela respondeu: "Nossa, Kamura! Esqueci de passar o pó". (Corpus 2014 Nivel de formalidade 3$)^{11}$

(4) Arrematei algumas blusas estilo ciganinha, várias blusas branquinhas de renda, guipir, e semelhantes... Um shorts jeans, com uma lavagem incrivel, que vestiu super bem! E só não levei a calça jeans flare, porque ficou um pouco grande... Mas era linda!! (Corpus 2014 - Nível de formalidade 1) ${ }^{12}$

$\mathrm{Na}$ ocorrência (3) o locutor Celso Kamura relata um episódio que viveu com a presidenta Dilma Rousseff. O maquiador faz uma avaliação negativa do fato de a presidenta Dilma ter aparecido "supersuada" na televisão, no dia do sorteio da Copa do Mundo. Além do posicionamento avaliativo do locutor, a construção "supersuada" indexa, ainda, focalização e da intensificação. Por meio do advérbio de intensidade "super", o locutor tanto intensifica (a presidenta estava mais do que muito suada, estava "supersuada") quanto coloca em relevo a informação que ele considera ser a mais importante no discurso ("suada").

$\mathrm{Na}$ ocorrência (4), a locutora avalia positivamente uma situação: ter arrematado boas peças de roupa em uma loja virtual. Através da construção "super bem”, ela se posiciona de maneira positiva sobre o fato de ter comprado um short jeans que teve um bom caimento. $\mathrm{O}$

\footnotetext{
${ }^{11}$ Disponível em: <https://istoe.com.br/345875_EU+ACALMO+A+PRESIDENTA+/>. Acesso em: 19 jun. 2015.

${ }^{12}$ Disponível em: <http://www.blogdapaulinha.com.br/>. Acesso em: 11 jun. 2015.
} 
advérbio de intensidade "super", além de intensificar o do modo como o short vestiu (o short não vestiu somente bem, o short "vestiu super bem"), coloca em proeminência uma informação muito importante do discurso. Nesse caso, o referente da focalização e da intensificação é a ação expressa pelo verbo "vestir".

Os exemplos (3) e (4) apresentam ocorrências da microconstrução avaliativa com "super", representada simbolicamente por $\left\{[\text { super }]_{\mathrm{op}}+[\mathrm{adj} / \mathrm{adv}]_{\mathrm{var}}\right\}^{\text {int/foc }}$. Essa microconstrução compõe o subesquema 1 da rede construcional proposta em nossa tese de Doutorado e, também, neste artigo. Nesse subesquema 1, "super"” desempenha a função de advérbio de intensidade, diante de adjetivo ou de advérbio. Através dessa microconstrução, o locutor realiza uma avaliação sobre si mesmo, sobre o outro ou sobre determinada realidade, atribuindo relevo àquilo que deseja chamar a atenção em seu discurso.

Mediante o mecanismo da analogização, outros elementos passam a compor e a modificar a construção no eixo paradigmático, como é o caso de "mega", a partir do exemplar “super". Observemos os exemplos a seguir:

(5) Como é super natural e leve é necessario a ajudinha do corretivo básico para esconder manchinhas de sol, espinhas, olheiras, pois a sua cobertura é bem mas bem leve. E como é indicado para todos os tipos de pele, é oilfree, porém eu tenho uma pele mega oleosa, apesar de passar um produtinho da nivea (q tb é bom e barato) dá uma segurada mass com o passar das horas dá uma derretidinha, pois não controla a oleosidade (já até comprei a base nova da avon, a personal $q$ controla a oleosidade e se adapta a cor, parece q mudaram a fórmula pq não tem mais aquele cheirinho básico de avon, mas testei só uma vez ainda não dá pra ter uma opinião de verdade sobre o produto). (Corpus $2008-B \log )^{13}$

(6) Começando pelo brunch maravilhoso no Garcia \& Rodrigues! Por lá, as sessões de boulangerie e rotisserie dividem as atenções com o restaurante e são uma ótima pedida pra aqueles sábados pósbalada forte, em que você vai dormir de manhã com uma fatia de pizza da Guanabara no bucho e acorda mega tarde, doida pra devorar o que ver pela frente! hehehe (Corpus $2011-B l o g)^{14}$

No exemplo (5), o advérbio de intensidade "mega" exprime o posicionamento avaliativo da locutora acerca de um hidratante tonalizante com filtro solar. Para a locutora, o produto não é muito eficaz para quem tem pele oleosa. Assim, com a construção "mega oleosa", a locutora avalia negativamente sua própria pele, colocando em foco a informação

\footnotetext{
${ }^{13}$ Disponível em: <https://www.2beauty.com.br/blog/2008/09/16/resenha-by-amanda-hidratante-tonalizantecom-filtro-solar-fps-23-peel-line/>. Acesso em: 11 jun. 2015.

${ }^{14}$ Disponível em: <http://www.garotasestupidas.com/dicas-gastronomicas-no-rj/>. Acesso em: 13 jun. 2015.
} 
que ela julga ser a mais importante no discurso e atribui grau intensivo ao adjetivo "oleosa" (sua pele não é somente oleosa, mas, sim, “mega oleosa”).

No exemplo (6), o locutor expressa uma avaliação positiva sobre o brunch no restaurante Garcia \& Rodrigues. Segundo ele, o brunch é "maravilhoso", é uma "ótima pedida" para quem "vai dormir de manhã" e "acorda mega tarde" e com fome. O advérbio de intensidade "mega", além de intensificar, também coloca em relevo o advérbio de tempo “tarde”. O referente da focalização e da intensificação explícita é o verbo "acordar".

Portanto, no subesquema 1 , representado simbolicamente por $\left\{[\mathrm{X}]_{\mathrm{op}}+\right.$ $\left.[\operatorname{adj} / \mathrm{adv}]_{\mathrm{var}}\right\}^{\mathrm{int} / \mathrm{foc}}, \mathrm{X}$ representa a possibilidade de preenchimento por "super" e "mega" - ou outros - para o posicionamento avaliativo do locutor mediante a intensificação explícita e a focalização.

No eixo sintagmático, a construção $\left\{[\text { super }]_{\mathrm{op}}+[\operatorname{adj} / \mathrm{adv}]_{\mathrm{var}}\right\}^{\text {int/foc }}$ sofre uma expansão semântica de intensificação para qualificação e para modalização, tendo o sentido de "super" se tornado mais complexo, mais pesado e indireto em termos de processamento cognitivo. Assumimos, desse modo, que a construção de intensidade explícita, por contiguidade, é neoanalisada em contextos de qualificação e de modalização, quando "super" passa a focalizar substantivos e verbos, conforme observamos nos exemplos seguintes:

(7) Carolina: A gente já mudou muito, mas ainda tem muito o que mudar. Porque se você passeia pelos canais o que vê é mulher com a bunda pra cima e o peito aparecendo. A bunda em primeiro plano, claro!

Juliana: O pior: ninguém reclama. Será preciso um supertrabalho para que essa mudança chegue no conteúdo de fato. Aquele vídeo do Porta dos Fundos do xaveco na rua [em que os papéis se invertem e a moça dispara a falar baixarias para o homem] está entre os dez vídeos mais vistos do canal. E os homens riem deles mesmo. Fora que eles estão cada vez mais pensando em cuidar do cabelo, não ter barriga... Isso é fato. (Corpus 2014 - Nivel de formalidade 2) ${ }^{15}$

(8) Eu trabalho há 20 anos na Conspiração, que é uma empresa formada por homens. E eu vi mulheres muito fortes passarem lá e não aguentaram a barra. Porque é difícil lidar com tanto homem. Eu super me dou com eles, mas tem que ter jogo de cintura o tempo inteiro. Por outro lado, a estrutura de produção hoje no mercado audiovisual é feminina. As mulheres estão em todos os cargos. Às vezes você está numa mesa com 15 mulheres. (Corpus 2014 - Nivel de formalidade 2) ${ }^{16}$

No exemplo (7), Carolina e Juliana, executivas que trabalham com televisão, cinema e internet, discutem sobre a representação feminina na TV brasileira. Embora as executivas

\footnotetext{
${ }^{15}$ Disponível em: $<$ https://revistatrip.uol.com.br/tpm/descontrole-de-qualidade>. Acesso em: 4 jun. 2015.

${ }^{16}$ Disponível em: <https://revistatrip.uol.com.br/tpm/descontrole-de-qualidade>. Acesso em: 7 jun. 2015.
} 
concordem que a televisão brasileira tem representado diversos tipos de mulheres, elas acreditam que ainda há muito o que evoluir. É nesse contexto que Juliana avalia que será preciso realizar "um supertrabalho" para que a mudança de fato aconteça. Por meio do adjetivo qualificativo "super", a locutora coloca em proeminência a informação que julga ser mais importante - "trabalho" -, ao mesmo tempo em que qualifica o trabalho e intensifica tal qualificação de maneira implícita (um trabalho de bastante qualidade).

No mesmo contexto comunicativo, no exemplo (8), Carolina responde à pergunta do entrevistador da revista "TPM" a respeito de como é trabalhar em uma empresa essencialmente masculina. Apesar de Carolina avaliar como sendo difícil lidar com tantos homens, sendo preciso "ter jogo de cintura", ela quebra a expectativa de sua própria avaliação negativa quando profere a proposição "Eu super me dou com eles”. Carolina utiliza o advérbio modalizador epistêmico "super" com o objetivo de focalizar o verbo reflexivo "me dou" e de asseverar sua afirmação de que se dá bem com os homens da empresa, já antecipando uma provável desconfiança do interlocutor em relação a seu discurso.

Nos exemplos (7) e (8), apresentamos ocorrências de microconstruções pertencentes aos subesquemas 2 e 3 respectivamente. A microconstrução $\left\{[\text { super }]_{\mathrm{op}}+[\mathrm{subs}]_{\mathrm{var}}\right\}^{\mathrm{int} / \mathrm{foc}}$, no subesquema 2, serve como modelo para a instanciação de novas microconstruções, como é o caso da micro $\left\{[\mathrm{mega}]_{\mathrm{op}}+[\mathrm{subs}]_{\mathrm{var}}\right\}^{\text {int/foc }}$. Já a microconstrução $\left\{[\text { super }]_{\mathrm{op}}+[\mathrm{verb}]_{\mathrm{var}}\right\}^{\text {int/foc }}$, no subesquema 3, serve como exemplar para o surgimento de microconstruções como $\left\{[\text { mega }]_{\mathrm{op}}\right.$ $\left.+[\mathrm{verb}]_{\mathrm{var}}\right\}^{\text {int/foc }}$. Vejamos os exemplos seguintes:

(9) Dolllashes: Os cilios de boneca também fazem parte dessa lista! Eu acho fofo, mas dou muito trabalho pro maquiador na hora de aplicá-los. Vamos combinar que dá um mega efeito e finaliza a maquiagem, né bloguetes? Gostei muito da maquiagem chique e clean da Luis Vuitton, com os cílios superpower. (Corpus 2011 $-B \log )^{17}$

(10) TPM: Não rolam comparações entre vocês e até mesmo com artistas como Fafá de Belém e banda Calypso?

Gaby Amarantos: Não. Eu megarrespeito artistas como a Fafá, que é maravilhosa. Acho a banda Calypso incrivel. Não tenho esse pensamento de que vou tomar o lugar delas. Vou conquistar o meu espaço, e quero interagir com todo mundo, agregar. (Corpus 2011 - Revista online) ${ }^{18}$

No exemplo (9), a locutora, por meio da construção "mega efeito", avalia positivamente os "cílios de boneca". Nesse contexto, "mega" desempenha a função

17 Disponível em: <http://www.blogdamariah.com.br/index.php/2011/11/dicas-de-make-da-harpers-bazaar/>. Acesso em: 11 jun. 2015.

${ }^{18}$ Disponível em: <https://revistatrip.uol.com.br/tpm/gaby-amarantos>. Acesso em: 7 jun. 2015. 
morfossintática de adjetivo qualificativo do substantivo "efeito", colocando em foco aquilo que o locutor pretende dar destaque no discurso. Nessa construção, a leitura intensiva de "mega" fica a cargo da interpretação do interlocutor, embora sua acepção original - de tamanho - deixe vestígios. Sendo assim, quando se fala em "mega efeito", pensa-se em um efeito de grande notoriedade e, também, de ótima qualidade.

No exemplo (10), a cantora Gaby Amarantos é questionada pela revista TPM se fazem comparações entre os cantores do Pará (como é seu caso) e Fafá de Belém e Banda Calypso. Gaby responde que não, posicionando-se de maneira expressiva ao dizer que "mega respeita" artistas como a Fafá. Por meio do advérbio modalizador "mega", a locutora coloca em proeminência a informação que pretende dar destaque - o verbo "respeito" -, ao mesmo tempo em que assevera sua proposição. Nesse caso, o uso do advérbio modalizador epistêmico asseverativo "mega", ainda, codifica a intenção do locutor de proteger sua face positiva diante da possibilidade de o interlocutor desconfiar de seu enunciado. Defendemos, desse modo, que a força intensiva é transformada em força asseverativa.

Enquanto a ocorrência em (9) é um exemplo da microconstrução $\left\{[\mathrm{mega}]_{\mathrm{op}}+\right.$ [subs] $]_{\text {var }}$, pertencente ao subesquema 2, a ocorrência em (10) é um exemplo da microconstrução $\left\{[\mathrm{mega}]_{\mathrm{op}}+[\mathrm{verb}]_{\mathrm{var}}\right\}^{\text {int/foc }}$, pertencente ao subesquema 3 .

Em síntese, o subesquema 1, representado simbolicamente por $\left\{[\mathrm{X}]_{\mathrm{op}}+[\mathrm{adj} / \mathrm{adv}]_{\mathrm{var}}\right\}$, articula o posicionamento avaliativo do locutor por meio da focalização e da intensificação explícita. Fazendo parte desse subesquema, descrevemos as microconstruções $\left\{[\text { super }]_{\mathrm{op}}+\right.$ $\left.[\mathrm{adj} / \mathrm{adv}]_{\mathrm{var}}\right\}$ e $\left\{[\mathrm{mega}]_{\mathrm{op}}+[\mathrm{adj} / \mathrm{adv}]_{\mathrm{var}}\right\}$. Já o subesquema 2, cuja representação simbólica é $\left\{[\mathrm{X}]_{\mathrm{op}}+[\mathrm{subs}]_{\mathrm{var}}\right.$, manifesta o posicionamento avaliativo do locutor por meio da focalização, da intensificação implícita e da qualificação, conforme observamos nas descrições das microconstruções $\left\{[\text { super }]_{\mathrm{op}}+[\mathrm{subs}]_{\mathrm{var}}\right\}$ e $\left\{[\mathrm{mega}]_{\mathrm{op}}+[\mathrm{subs}]_{\mathrm{var}}\right.$. Por fim, o subesquema 3, representado formalmente por $\left\{[\mathrm{X}]_{\mathrm{op}}+[\mathrm{verb}]_{\mathrm{var}}\right\}$, exprime focalização, intensificação implícita e modalização, de acordo com o que evidenciamos nas descrições das microconstruções $\left\{[\text { super }]_{\mathrm{op}}+[\mathrm{verb}]_{\mathrm{var}}\right\}$ e $\left\{[\mathrm{mega}]_{\mathrm{op}}+[\mathrm{verb}]_{\mathrm{var}}\right.$.

Cada uma das microconstruções aqui analisadas evidenciam que, além de apresentarem similaridades, possuem particularidades que as identificam e as alocam em diferentes subesquemas. 
Segundo o Princípio da Não-Sinonímia de Goldberg (1995), duas construções ou mais, cuja estrutural formal é diferente, são semanticamente ou pragmaticamente distintas. É nesse contexto que assumimos, com base nas análises qualitativa e quantitativa dos dados, que haveria uma diferença de expressividade entre as microconstruções com "super" e as microconstruções com "mega" que estaria relacionada às suas acepções de origem. A acepção original de "super" aponta para uma localização em posição vertical; enquanto a acepção original de "mega" aponta para tamanho/dimensão. O próprio falante julga que "mega" é mais expressivo do que "super", como pudemos observar em construções justapostas encontradas no corpus, em que em uma escala de expressividade, "super" aparece majoritariamente em posição inicial (em um total de 39 ocorrências construções justapostas, "super" ocorre em posição inicial em 34 delas). Vejamos dois exemplos:

(11) Escolhi duas peças da linha Loungewear para usar no evento. Este short é superhipermega fofo e fica lindo com flat ou com salto, depende da ocasião. Eu até usaria este look com aquele sapato Valentino de tachas, sabe? (Corpus 2014 - Nivel de formalidade 1) ${ }^{19}$

(12) É um intensificador de perfume pras roupas no formato de pérolas, que a gente coloca na máquina de lavar (antes do sabão e amaciante) e deixa a roupa com um perfume suuuupermegahiper cheiroso! (Corpus 2014 - Nivel de formalidade 1) ${ }^{20}$

As ocorrências em (11) e em (12) são exemplos das 34 construções justapostas encontradas no corpus, em que "super" ocorre em posição inicial no que se refere aos outros elementos - como em (11), antes de "hipermega", e em (12), antes de "megahiper".

Portanto, defendemos, nesse artigo, que as microconstruções com "super" estariam mais avançadas no processo de construcionalização gramatical e atuariam como exemplares na rede construcional apresentada.

\section{Considerações finais}

Embora tenhamos tratado dos dados em uma perspectiva sincrônica de análise, demonstramos, neste trabalho, a partir do estabelecimento dos níveis esquemáticos e da rede

\footnotetext{
${ }^{19}$ Disponível em: <http://www.blogdamariah.com.br/index.php/2014/10/inauguracao-hering-for-you/>. Acesso em: 6 jun. 2015.

${ }^{20}$ Disponível em: <http://www.blogdamariah.com.br/index.php/2014/09/downy/>. Acesso em: 6 jun. 2015.
} 
construcional que envolvem as construções avaliativas com "super" e "mega" na língua portuguesa, que é possível evidenciar a instanciação e a convencionalização de novas microconstruções na língua a partir do ponto de vista da analogização.

Nesse contexto, verificamos que a construção mais esquemática $\left\{[\mathrm{X}]_{\mathrm{op}}+[\mathrm{Y}]_{\mathrm{var}}\right\}^{\mathrm{int} / \mathrm{foc}}$, de caráter mais procedural, que indexa o posicionamento avaliativo do locutor com atitudes intensiva e focalizadora, constitui um pareamento convencionalizado na língua, que compreende diferentes nós hierárquicos e interligados por elos - descritos em forma de subesquemas e microconstruções.

Sendo assim, acreditamos ter respondido à seguinte questão de pesquisa deste artigo: seria possível a investigação da construcionalização gramatical mediante uma perspectiva sincrônica de análise?

Procuramos demonstrar, com o presente trabalho, que a análise sincrônica também é capaz de refletir a atração morfossintática e semântico-pragmática e a extensibilidade de padrões, para diferentes contextos discursivos, a partir de representações exemplares, permitindo, assim, a verificação do resultado de um processo de construcionalização gramatical a partir da perspectiva da analogização.

É nesse contexto que assumimos que o modelo elaborado por Traugott e Trousdale (2013) é capaz de dar conta da investigação de construções que articulam esquemas construcionais na língua que estão disponíveis para o acesso do locutor no momento da interação comunicativa. E, assim, pretendemos contribuir para as pesquisas que tem como objetivo a explicação da mudança linguística em uma amostra sincrônica.

\section{Referências}

BYBEE, J. L. Language, usage and cognition. Cambridge: Cambridge University Press, 2010 .

BISPO, E. B.; SILVA, J. R. Variação linguística, mudança linguística e construcionalização.In: XXI Seminário do Grupo de Estudos Discurso \& Gramática e VIII Seminário Internacional do Grupo de Estudos Discurso \& Gramática. Rio de Janeiro: UFRJ, 2016. 
CROFT, W. Radical construction grammar: syntactic theory in typological perspective. New York: Oxford University Press, 2001.

CUNHA LACERDA, P. F. A. da. O papel do método misto na análise de processos de mudança em uma abordagem construcional: reflexões e propostas. Revista LinguíStica / Revista do Programa de Pós-Graduação em Linguística da Universidade Federal do Rio de Janeiro. Volume Especial, dez de 2016, p. 83-101.

FURTADO DA CUNHA, M. A.; BISPO, E. B.; SILVA, J. R. Linguística funcional centrada no uso: conceitos básicos e categorias analíticas. In: CEZÁRIO, M. M.; FURTADO DA CUNHA, M. A. (Orgs.). Linguística centrada no uso: uma homenagem a Mário Martelotta. Rio de Janeiro: Mauad, 2013, p. 13-44.

GOLDBERG, A. E. Constructions: a construction grammar approach to argument structure. Chicago: University of Chicago Press, 1995.

. Constructions at work: the nature of generalization in language. Oxford: Oxford University Press, 2006.

A constructionist approach to language. In: Workshop em XXI Seminário do Grupo de Estudos Discurso \& Gramática e VIII Seminário Internacional do Grupo de Estudos Discurso \& Gramática, 2016.

HOPPER, P. J. On some principles of grammaticization. In: TRAUGOTT, E. C.; HEINE, B. (Eds.). Approaches to grammaticalization. v. I. Philadelphia: John Benjamins Company, 1991, p.17-35. 1997.

.; TRAUGOTT, E. C. Grammaticalization. Cambridge: Cambridge University Press,

LABOV, W. Padrões sociolinguísticos. Tradução de Marcos Bagno, Maria Marta Pereira Scherre, Caroline Rodrigues Cardoso. São Paulo: Parábola Editorial, 2008.

LEHMANN, C. Grammaticalization: Synchronic variation and diachronic change. Lingua e Stile, Bologna, v.20, p. 303-318, 1985.

MARTELOTTA, M. E. Mudança linguística: uma abordagem baseada no uso. São Paulo: Cortez, 2011.

MARTINS DALL'ORTO. Construções avaliativas com "super", "mega", "hiper" e "ultra" na língua portuguesa: uma proposta de rede construcional a partir da linguística funcional centrada no uso. Tese de Doutorado. Universidade Federal de Juiz de Fora, MG, 2018.

NEVES, M. H. de M. A gramática funcional. São Paulo: Martins Fontes, 1997.

ROSÁRIO, I. da C. do; OLIVEIRA, M. R. de. Funcionalismo e abordagem constructional da gramática. Alfa, São Paulo, 60 (2), p. 233-259, 2016. 
.; LOPES, M. G. Construcionalização gramatical em perspectiva sincrônica. In: Apresentação em XXII Seminário Nacional e IX Seminário Internacional do Grupo de Estudos Discurso \& Gramática. Niterói: UFF, 2017.

TRAUGOTT, E. C. Grammaticalization, constructions and the incremental development of language: suggestions from the development of degree modifiers in English. In: ECKARDT, R.; JÄGER, G.; VEENSTRA, T. V. (Eds.). Variation, Selection, Development: Probing the Evolutionary Model of Language Change. Berlin/New York: Mouton de Gruyter, 2008, p. 219-250.

.; Grammaticalization and mechanisms of change. In: NARROG, H.; HEINE, B. (Eds.). The Oxford handbook of grammaticalization. New York: Oxford University Press, 2011a, p. 19-30.

. Pragmatics and language change. In: ALLAN, K.; JASZCZOLT, K. M. (Eds.). The Cambridge Handbook of Pragmatics. Cambridge: Cambridge University Press, 2011b, p. 549-565.

. Toward a coherent account of grammatical constructionalization, Slightly revised version of powerpoint presentation at Societas Linguistica Europea (SLE) 44, Spain, September 8th-11th, $2011 \mathrm{c}$. Press, 2005.

.; DASHER, R. Regularity in semantic change. New York: Cambridge University .; TROUSDALE, G. Constructionalization and Constructional Changes. Oxford: Oxford University Press, 2013.

VITRAL, L. O papel da frequência na identificação de processos de gramaticalização. Scripta, vol. 9, n. 18. Belo Horizonte, 2006, p. 149-177.

\section{Synchronic grammatical constructionalization: evidence based on the analysis of evaluative constructions with "super" and "mega" in the Portuguese language}

\footnotetext{
Abstract: This paper aims to discuss the role of the synchronic perspective of analysis in the grammatical constructionalization. In order to fulfill the proposed objective, the qualitative and quantitative analyzes (CUNHA LACERDA, 2016) of the constructions with "super" and "mega" in the Portuguese language were carried out, considering the distribution of the data in the contemporary Portuguese. In this study, we assume the theoretical assumptions of the model proposed by Traugott and Trousdale (2013), especially regarding the definitions of language, construction and network and with regard to the process of constructionalization, and we discuss the expression "synchronic grammatical" that was proposed by Rosário and Lopes (2017). The results of the research show that, in the studies about the synchronic grammatical constructionalization of evaluative constructions with "super" and "mega", it is possible to highlight the important performance of the analogy mechanism (TRAUGOTT, 2011a). And in this context we demonstrate, through the proposition of a 


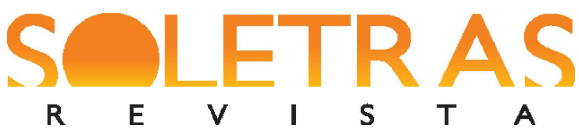

N.37 - 2019.1 - LAURIÊ FERREIRA MARTINS DALL'ORTO

constructional network, that individual microconstructions are related to general and abstract schemes at the same time that they are affected by them.

Keywords: Synchronic grammatical constructionalization. Analogization. Constructional network.

Recebido em: 8 de dezembro de 2018.

Aceito em: 13 de abril de 2019. 